\title{
Amniotic Membrane in the Treatment of Spinal Cord Injuries
}

\author{
Emilia Angela LoSchiavo Arisawa ${ }^{1 *}$, Luciana Barros Sant'Anna ${ }^{2}$, Mariana de Castro Nicodemo ${ }^{1}$, Eduarda \\ Cesar da Luz Oliveira ${ }^{1}$ and Débora Campos Chaves $^{1}$
}

${ }^{1}$ Biostimulation and Tissue Repair Laboratory, University of Paraíba Valley, Brazil

${ }^{2}$ Histology and Regenerative Therapy Laboratory, University of Paraíba Valley, Brazil

Received: October 25, 2017; Published: October 30, 2017

*Corresponding author: Emilia Angela Lo Schiavo Arisawa, Biostimulation and Tissue Repair Laboratory, University of Paraíba Valley, 2911 Shishima Hifumi Avenue, São José dos Campos, São Paulo, Brazil; Email: mirela@univap.br

Abbreviations : SCI: Spinal Cord Injury; AM: Amniotic Membrane; AECs: Amniotic Epithelial Cells; AMSC: Amniotic Mesenchymal Stromal Cells

\section{Mini Review}

Spinal cord injury (SCI) is one of the most common and devastating injuries found in the neurological clinic [1,2]. It is defined as damage to the spinal cord that causes temporary or permanent changes in its function, resulting in significant neurological dysfunction and disability [3,4]. SCI has physical, social and occupational consequences for patients and their families, resulting in loss of independence and an increase in the mortality rate [3]. In addition, studies show that expenses for care of patients with SCI can reach US\$1.1-4.6 million per patient throughout life. Thus, it is extremely important to develop effective treatments [5] This type of injury can cause many disorders, depending on his localization and severity. According to Castro, the number of people with some type of physical disability has increased in the past few years [6]. A partial spinal cord injury is sufficient to cause permanent disabilities, such as the Brown-Sequard syndrome, often observed after spinal cord hemisection [7]. Currently, surgical treatment for mechanical stabilization and decompression has been performed in cases of unstable fractures with spinal cord injury and the use of drugs to treat such lesions has been extensively studied [8].

In the last three decades, numerous neuroprotective and neuroregenerative therapies have been transferred from preclinical studies to clinical trials [3]. However, it is still not possible to find standard therapy universally accepted and new therapeutic approaches are needed [4]. Experimental and clinical studies evidenced that spinal cord suffers primary and secondary damages after acute injury [9]. Primary injury occurs with the initial traumatic event that produces immediate mechanical disruption and displacement of the spine, which causes compression or transection of the spinal cord [3]. There are rupture of meninges, hemorrhage and massive death of neurons, oligodendrocytes and astrocytes [10]. Together, these events immediately initiate a cascade of secondary lesions, which cyclically results in the death of neurons and glial cells, ischemia and inflammation, resulting in further damage to the spinal cord and neurological dysfunction [3]. After these secondary damages, changes in the organization and structural architecture of the spinal cord occur, including the formation of cystic cavities and a glial scar, causing a physical barrier to axonal regeneration $[3,10,11]$. The glial scar and cystic cavities, in combination with poor endogenous remyelination and axonal growth, prove that the spinal cord has a low potential for intrinsic recovery, thus SCI causes permanent neurological deficits [3].

The treatment and functional reconstruction of an injury in the central nervous system constitute a challenge for health areas. A growing number of researchers have attempted to apply neural stem cells combined with artificial materials for nerve repair. However, these approaches are challenged by ethical and practical issues. Amniotic tissue, on the other hand, is a clinical product of discard and amniotic epithelial cells are pluripotent, with low immunogenicity and are not the subject of ethical debate [12]. Amniotic membrane (AM), innermost layer of the fetal membranes, is composed of three histologically distinct layers: the epithelial layer, the basement membrane and avascular mesenchymal/ stromal layer. The epithelial layer comprises a flat, cuboidal and columnar cells uniformly disposed on the basement membrane, which consists mainly of collagen IV, elastin, fibronectin, laminin and proteoglycans. The mesenchymal layer in turn consists of three regions: an acellular compact layer, that forms the main fibrous 
skeleton of the AM composed of collagens I, III and fibronectin; a network of dispersed fibroblast-like mesenchymal cells; and a spongy layer of loosely arranged collagen fibers that separates the amniotic membrane from the chorion [13].

Both cell types isolated from AM, amniotic epithelial cells (AECs) and amniotic mesenchymal stromal cells (AMSC), express stem cell markers and have the ability to differentiate toward all three germ layers [14]. AECs have been used in several researches to study the damaged tissues repair and experimental evidence has demonstrated its great regenerative potential for various tissues [14-16]. In addition, AECs have some properties similar to neural and glial cells and ability to secrete neurotransmitters [17-19]. Thus, these cells have great potential in the treatment of SCI. Sankar demonstrated in his study that AECs survive in the transplanted environment, support the growth of axons through them, preventing glial scar formation at the site of injury and the death of damaged neurons. These results are similar to those found in neural transplantation studies. Thus, it is believed that AECs may exhibit the same properties of neural tissue, regarding the beneficial effects on repair of SCI [20]. Roh also obtained good results when applying AECs in SCI induced in rats. His results demonstrated that transplantation of AECs has a beneficial effect on SCI-induced neuropathic pain [21]. Gao investigate the synergistic effects of anti-inflammatory drug administration and transplantation of AECs following SCI in rats. He stated that this combination reduced the secondary damage and promoted functional recovery after SCI [1].

However, in order to improve the results obtained in the treatment of this type of lesion, studies have used AECs combined with scaffolds. They stated that this combination resulted in a lower glial scar in the damaged region when compared to animals that received only AECs. These animals also had lower inflammatory infiltrate and improved motor function. Scaffolding provided a more favorable environment for regeneration of the central nervous system, ensuring that transplanted cells had a growth surface and promoted cell adhesion [12]. In this context, several studies have chosen to use the AM as a fragment, rather than isolated AECs. This protocol allows to preserve the micro-environment with all the growth factors and differentiation factors present, providing action of these chemical mediators in the injured tissue repair process. In addition, it also facilitates the processing and use of AM AM patching provides to the injured tissue mechanical protection, anti-adhesive effect, wound protection and migration and adhesion of basal epithelial cells. In addition, studies show that AM has several useful properties for the proper development of the repair process: reduction of fibrosis, prevention of apoptosis, restoration of the epithelial phenotype, antibacterial action, anti-inflammatory action, protease inhibitor, low immunogenicity and does not induce rejection after transplantation [22-24].

Other studies have demonstrated the great potential of using AM fragments on the treatment of other tissue injuries. Cargnoni [25] applied AM as a patch to reduce the induced necrosis in rat hearts and Sant'Anna [26] demonstrated that AM application reduced liver fibrosis induced by bile duct ligation when it was applied around the rat liver. Furthermore, Nicodemo demonstrated in her study that human amniotic membrane fragment application on acute lesion in the Achilles tendon of rats favored the evolution of tissue repair, reduced the inflammatory response, induced the proliferation of fibroblasts and collagen fibers, and allowed a reduction in healing process time [27]. In clinical practice, it has also been applied in ophthalmology since 1997 [28]. It is used therapeutically for defects of the cornea and conjunctiva [29]; prevention of postoperative adhesions [30]; reconstruction of defects of the pharynx and oral mucosa [31] and in bone defects [32]. In general, $A M$ patching has shown interesting results when applied in injured tissue, with low incidence of side effects, encouraging the development of new experimental research aimed at the treatment of SCI. Further studies are needed to determine the effects of this treatment protocol on the development of the SCI repair process.

\section{References}

1. Gao S, Ding J, Xiao HJ, Li ZQ, Chen Y, et al. (2014) Anti-inflammatory and anti-apoptotic effect of combined treatment with methylprednisolone and amniotic membrane mesenchymal stem cells after spinal cord injury in rats. Neurochemical research 39(8): 1544-1552.

2. Lee BB, Cripps RA, Fitzharris M, Wing PC (2014) The global map for traumatic spinal cord injury epidemiology: update 2011, global incidence rate. Spinal cord 52(2): 110-116.

3. 3. Ahuja CS, Wilson JR, Nori S, Kotter MRN, Druschel C, et al. (2017) Traumatic spinal cord injury. Nature Reviews Disease Primers 3(17018): $1-21$.

4. Baptiste DC, Fehlings MG (2007) Update on the treatment of spinal cord injury. Progress in brain research 161: 217-233.

5. National Spinal Cord Injury Statistical Center (2014) Spinal cord injury Facts and figures at a glance.The journal of spinal cord medicine 37(1): 117-118.

6. Castro S (2008) Deficiência visual, auditiva e física: prevalência e fatores associados em estudo de base populacional. Cadernos de Saúde Pública 24(8): 1773-1782.

7. 7. Murphy MN, Ichiyama RM, Iwamoto GA, Mitchell JH, Smith SA (2013) Exercise pressor reflex function following acute hemi-section of the spinal cord in cats. Frontiers in physiology 4(3): 1-8.

8. Souza FI, Cristante AF, Marcon RM, Ferreira R, Santos GB, et al. (2013) Monossialogangliosídeo transdérmico com laser no tratamento de lesão medular espinal de ratos. Acta Ortopédica Brasileira 21(2): 87-91.

9. Tator CH (1995) Update on the pathophysiology and pathology of acute spinal cord injury. Brain pathology 5(4): 407-413.

10. Horky LL, Galimi F, Gage FH, Horner PJ (2006) Fate of endogenous stem/ progenitor cells following spinal cord injury. J Comp Neurol 498(4): 525538.

11. Thuret S, Moon LD, Gage FH (2006) Therapeutic interventions after spinal cord injury. Nature Reviews Neuroscience 7(8): 628-643.

12. Wang TG, Xu J, Zhu AH, Lu H, Miao ZN, et al. (2016) Human amniotic epithelial cells combined with silk fibroin scaffold in the repair of spinal cord injury. Neural regeneration research 11(10): 1670-1677.

13. Mamede AC, Carvalho MJ, Abrantes AM, Laranjo M, Maia CJ, et al. (2012) Amniotic membrane: from structure and functions to clinical applications. Cell and Tissue Research 349(2): 447-458.

14. Miki T, Lehmann T, Cai H, Stolz DB, Strom SC (2005) Stem cell characteristics of amniotic epithelial cells. Stem cells 23(10): 15491559. 
15. Tamagawa T, Ishiwata I, Saito S (2004) Establishment and characterization of a pluripotent stem cell line derived from human amniotic membranes and initiation of germ layers in vitro. Human cell 17(3): 125-130.

16. Parolini O, Soncini M, Evangelista M, Schmidt D (2009) Amniotic membrane and amniotic fluid-derived cells: potential tools for regenerative medicine? Regenerative medicine 4(2): 275-91.

17. Sakuragawa N, Thangavel R, Mizuguchi M, Hirasawa M, Kamo IM (1996) Expression of markers for both neuronal and glial cells in human amniotic epithelial cells. Neuroscience letters 209(1): 9-12.

18. Elwan MA, Sakuragawa N (1997) Evidence for synthesis and release of catecholamines by human amniotic epithelial cells. Neuroreport $8(16)$ : 3435-3438.

19. Sakuragawa N, Misawa H, Ohsugi K, Kakishita K, Ishii T, et al. (1997) Evidence for active acetylcholine metabolism in human amniotic epithelial cells: applicable to intracerebral allografting for neurologic disease. Neuroscience letters 232(1): 53-56.

20. Sankar V, Muthusamy R (2003) Role of human amniotic epithelial cell transplantation in spinal cord injury repair research. Neuroscience 118(1): 11-17.

21.21. Roh DH, Seo MS, Choi HS, Park SB, Han HJ, et al. (2013) Transplantation of human umbilical cord blood or amniotic epithelial stem cells alleviates mechanical allodynia after spinal cord injury in rats. Cell transplantation 22(9): 1577-1590.

22. Tseng SC (2001) Amniotic membrane transplantation for ocular surface reconstruction. Bioscience reports 21(4): 481-489.

23. Cremonini DN, Ranzani JJT, Marques MEA, Rodrigues GN, Brandão CVS (2007) Transplante de membrana amniótica canina criopreservada para cicatrização de córnea com deficiência de células límbicas em coelhos Arquivo Brasileiro de Medicina Veterinária e Zootecnia 59(6): 14621467.
24. Manuelpillai U, Moodley Y, Borlongan CV, Parolini O (2011) Amniotic membrane and amniotic cells: potential therapeutic tools to combat tissue inflammation and fibrosis? Placenta 32(4): 320-325.

25. Cargnoni A, Di Marcello M, Campagnol M, Nassuato C, Albertini A, et al. (2009) Amniotic membrane patching promotes ischemic rat heart repair. Cell transplantation 18(10): 1147-1159

26. Sant'Anna LB, Cargnoni A, Ressel L, Vanosi G, Parolini O (2011) Amniotic membrane application reduces liver fibrosis in a bile duct ligation rat model. Cell transplantation 20(3): 441-453.

27. Nicodemo MDC, Neves LRD, Aguiar JC, Brito FDS, Ferreira I, et al. (2017) Amniotic membrane as an option for treatment of acute Achilles tendon injury in rats. Acta Cirurgica Brasileira 32(2): 125-139.

28. Tseng SC, Prabhasawat P, Lee SH (1997) Amniotic membrane transplantation for conjunctival surface reconstruction. American journal of ophthalmology 124(6): 765-774.

29. Malhotra C, Jain AK (2014) Human amniotic membrane transplantation: different modalities of its use in ophthalmology. World journal of transplantation 4(2): 111-121.

30. Kassem RR, Khodeir MM, Salem M, Abdel-Hamid MA, El-Mofty RM, et al. (2013) Effect of cryopreserved amniotic membrane on the development of adhesions and fibrosis after extraocular muscle surgery in rabbits. Acta ophthalmologica 91(2): 140-148.

31. Khademi B, Bahranifard H, Azarpira N, Behboodi E (2013) Clinical application of amniotic membrane as a biologic dressing in oral cavity and pharyngeal defects after tumor resection. Archives of Iranian medicine 16(9): 503-506.

32. Starecki M, Schwartz JA, Grande DA (2014) Evaluation of amnioticderived membrane biomaterial as an adjunct for repair of critical sized bone defects. Advances in Orthopedic Surgery 2014(2014): 14.

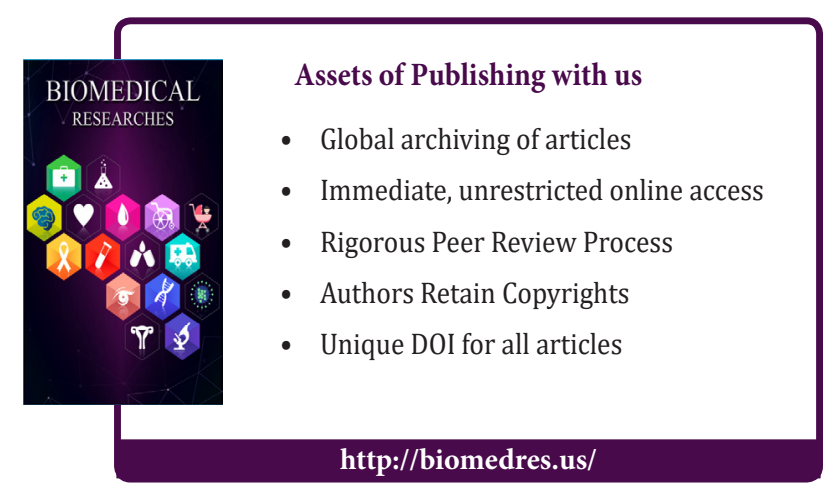

